PUBLIC HEALTH RESEARCH

\title{
Aetiologies of Liver Cirrhosis among Adult Patients Attending A Hepatology Clinic at Selangor, Malaysia
}

\author{
Chieng Jin Yu ${ }^{1 *}$, Pan Yan ${ }^{2}$ Liew Chiat Fong ${ }^{3}$, Mazawawi Muhammad and Syed Anas Tamamulqomar Said \\ Abu Hassan \\ ${ }^{1}$ Department of Medicine, Pantai Hospital Ampang, Jalan Perubatan 1, Pandan Indah, 55100 Kuala Lumpur, \\ Malaysia. \\ ${ }^{2}$ Division of Biomedical Sciences, School of Pharmacy, University of Nottingham Malaysia, 43500 Semenyih, \\ Selangor, Malaysia. \\ ${ }^{3}$ Department of Medicine, Sungai Buloh Hospital, Jalan Hospital, 47000 Sungai Buloh, Selangor, Malaysia. \\ ${ }^{4}$ Faculty of Medicine and Health Sciences, Putra University of Malaysia, 43400 UPM Serdang, Selangor, \\ Malaysia.
}

*For reprint and all correspondence: Chieng Jin Yu, Department of Medicine, Pantai Hospital Ampang, Jalan Perubatan 1, Pandan Indah, 55100 Kuala Lumpur, Malaysia.

Email:cjy511@yahoo.com

\section{ABSTRACT}

\begin{tabular}{|c|c|}
\hline Introduction & Liver cirrhosis is an important cause of morbidity and mortality. \\
\hline Methods & $\begin{array}{l}\text { Our study aimed to describe the aetiologies of liver cirrhosis and its associated } \\
\text { risk factors among adult patients attending the Hepatology Clinic, Serdang } \\
\text { Hospital, Malaysia from 1st January } 2010 \text { to } 30 \text { th June } 2017 \text {. Aetiology was } \\
\text { determined by patients' medical history as well as biochemical and/or } \\
\text { histological findings. The severity of the liver cirrhosis, together with the } \\
\text { presence of complications and incidence of hepatocellular carcinoma were } \\
\text { documented. }\end{array}$ \\
\hline Results & $\begin{array}{l}\text { A total of } 357 \text { adult patients were diagnosed with liver cirrhosis including } 199 \\
\text { male patients }(55.7 \%) \text { and } 158 \text { female patients }(44.3 \%) \text {, with a mean age of } \\
54 \text {-year-old (range: } 28-84 \text {-year-old). The determined most likely causes of } \\
\text { liver cirrhosis were chronic hepatitis B }(\mathrm{N}=145,40.6 \%) \text {, chronic hepatitis C } \\
(\mathrm{N}=67,18.8 \%) \text {, cryptogenic liver disorder }(\mathrm{N}=63,17.6 \%) \text {, alcohol }(\mathrm{N}=42 \text {, } \\
11.8 \%) \text {, non-alcoholic fatty liver disease }(\mathrm{N}=25,7.0 \%) \text {, and others }(\mathrm{N}=15 \text {, } \\
4.2 \%) \text {. Chronic hepatitis B was predominant among Chinese whereas alcohol } \\
\text { consumption was mainly found among Indians, and Hepatitis C-linked liver } \\
\text { cirrhosis was highest among Malays. Majority of the patients had compensated } \\
\text { cirrhosis with Child-Pugh A }(\mathrm{N}=221,61.9 \%) \text { at the time of diagnosis. } 80.4 \% \\
(\mathrm{~N}=287) \text { of the cirrhotic patients had performed at least one endoscopy } \\
\text { surveillance, with } 28.6 \%(82 / 287) \text { of them had endoscopic evidence of portal } \\
\text { hypertension. } 32.2 \% \text { of patients had at least one hospitalization due to } \\
\text { complication of cirrhosis. } 41 \text { patients }(11.5 \%) \text { had concurrent hepatocellular } \\
\text { carcinoma during the follow up. }\end{array}$ \\
\hline Conclusions & $\begin{array}{l}\text { Hepatitis B viral infection remains the most common cause of cirrhosis among } \\
\text { patients attending Hepatology Clinic, Serdang Hospital. }\end{array}$ \\
\hline Keywords & Aetiology - liver cirrhosis - Malaysia. \\
\hline
\end{tabular}

Article history

Received: 20 October 2020

Accepted: 4 November 2021

Published: 1 March 2022 


\section{INTRODUCTION}

Liver cirrhosis is a progression of hepatic fibrosis and replacement of the healthy liver tissues by scarring, that takes few months to years. Cirrhosis is one of common causes of mortality and morbidity worldwide and remains a burden to public health. ${ }^{1}$

The aetiology of cirrhosis differs geographically and socioeconomically, with alcoholism, chronic hepatitis $\mathrm{C}(\mathrm{CHC})$, and nonalcoholic fatty liver disease (NAFLD) being more common reported in western countries, ${ }^{2-4}$ while chronic hepatitis $\mathrm{B}$ (CHB) as the most common cause of liver cirrhosis in Asia (Hong Kong, ${ }^{5}$ South Korea, ${ }^{6}$ India, ${ }^{7}$ Iran, ${ }^{8}$ Singapore) ${ }^{9}$ However, this was different in Japan ${ }^{10}$, in which CHC was the major aetiology leading to the cirrhosis. In recent years, the increasing incidence of overweight or obesity, diabetes mellitus and metabolic syndrome among the younger population in Malaysia, which could be due to sedentary lifestyle, may have an incremental impact on the risk of developing NAFLD among Malaysians. ${ }^{11}$

The indication for hospitalization among cirrhotic patients is frequently due to consequences of portal hypertension, decompensation or complication, especially ascites, variceal bleeding, jaundice, hepatic encephalopathy, and hepatocellular carcinoma (HCC). ${ }^{12}$ Approximately half of the cirrhotic patients have endoscopic evidence of varices, and one-third of them developed variceal bleeding. ${ }^{13,} 14$ Therefore, esophagogastroduodenoscopy (OGDS) was advised to be performed early to evaluate the risk of variceal bleeding, followed by appropriate prophylactic management either by pharmacologic or endoscopic variceal band ligation (EVL).

Cirrhosis itself is well known as a factor leading to development of HCC. ${ }^{15}$ Based on GLOBOCAN 2020, ${ }^{16}$ HCC contributed to $4.4 \%$ of new cases of malignancies and $6.9 \%$ of cancer mortalities in Malaysia. The risk of developing HCC depends on the underlying aetiology of the cirrhosis. Kato $\mathrm{Y}$ et al. had noticed the rate of developing HCC was significantly higher in the $\mathrm{CHB}$ or $\mathrm{CHC}$ group than in the non-B non-C groups. ${ }^{17}$ This was further reported in the REVEAL-HBV study that involved 3160 participants: $\mathrm{CHB}$ with a higher viral load had been reported as a strong factor leading to HCC. ${ }^{18}$

Malaysia is a country with national population of approximately 32 million, with three major ethnic groups, Malays (61.7\%), Chinese $(20.8 \%)$ and Indian $(6.2 \%)$ who have different believes and cultural practices. This unique multiethnic makeup of population is quintessential in studying the impact of ethnicity on the characteristics of a variety liver diseases. Viral hepatitis was known as the major aetiology of cirrhosis among Malaysians. ${ }^{19,}{ }^{20}$ It was transmitted by vertical transmission during birth or shortly after birth, and horizontal transmission via exposure to infected blood or body fluids. However, according to the scarce data describing the patterns of liver cirrhosis in Malaysia, the epidemiology of liver cirrhosis is different between ethnic groups, gender, and geographic regions. ${ }^{19}$ This could be explained by the epidemiology of $\mathrm{CHB}$ and $\mathrm{CHC}$ and also the alcohol drinking pattern in the population.

The study aimed to determine the association between the demographic factors and the aetiologies of liver cirrhosis among the patients at Serdang Hospital. Besides, the prevalence of complications of liver cirrhosis together with incidence of HCC were further analysed as well.

\section{MATERIALS AND METHODS}

Retrospectively, the data among cirrhotic patients attending the Hepatology Clinic at Serdang Hospital from the period of $1^{\text {st }}$ January 2010 to $30^{\text {th }}$ June 2017 were collected via hospital Electronic Health Information System (EHIS). Serdang Hospital is a government-funded multi-specialty hospital with 620 beds, which is located in Sepang district, Selangor. All cirrhotic patients aged at least 18-yearold, with complete records and follow-up were included. The diagnosis of liver cirrhosis was made based on patient's clinical data with either a positive radiologic or pathologic result (i.e., ultrasonography, computerized tomography (CT) scan or liver biopsy). Patient's demographic characteristics (gender, age, ethnicity), aetiology of liver cirrhosis (based on patient's history and clinical presentation, biochemical, serological and histological tests), OGDS findings, Child-Pugh scoring at the time of diagnosis, together with complication, and incidence of HCC during the time of clinic follow up were extracted and further analysed. Paired t test and one-way ANOVA were performed using GraphPad Prism version 8.0.0 for Windows, GraphPad Software, San Diego, California USA, www.graphpad.com". This research was registered in accordance with the National Medical Research Register Malaysia and ethics approval was granted before the commencement of the data collection.

\section{RESULTS}

Demographics characteristics and aetiology distribution analysis

A total of 357 patients were recruited in this study. Fig. 1 provided the overall aetiological profile of liver cirrhosis among the collected data. CHB $(40.6 \%)$ was the most common aetiology of cirrhosis among the patients. This was followed by CHC (18.8\%), cryptogenic (17.6\%), alcoholic $(11.8 \%)$, and NAFLD (7.0\%), AIH (1.4\%), coinfection of hepatitis B and C (1.4\%), PBC $(0.8 \%)$, Wilson's disease $(0.3 \%)$ and drug induced $(0.3 \%)$. Among these patients, $55.5 \%$ of the patient belonged to the age group of $40-59$ years, and the mean age 
was 54 years. The youngest patient was 28 years old and oldest 84 years.

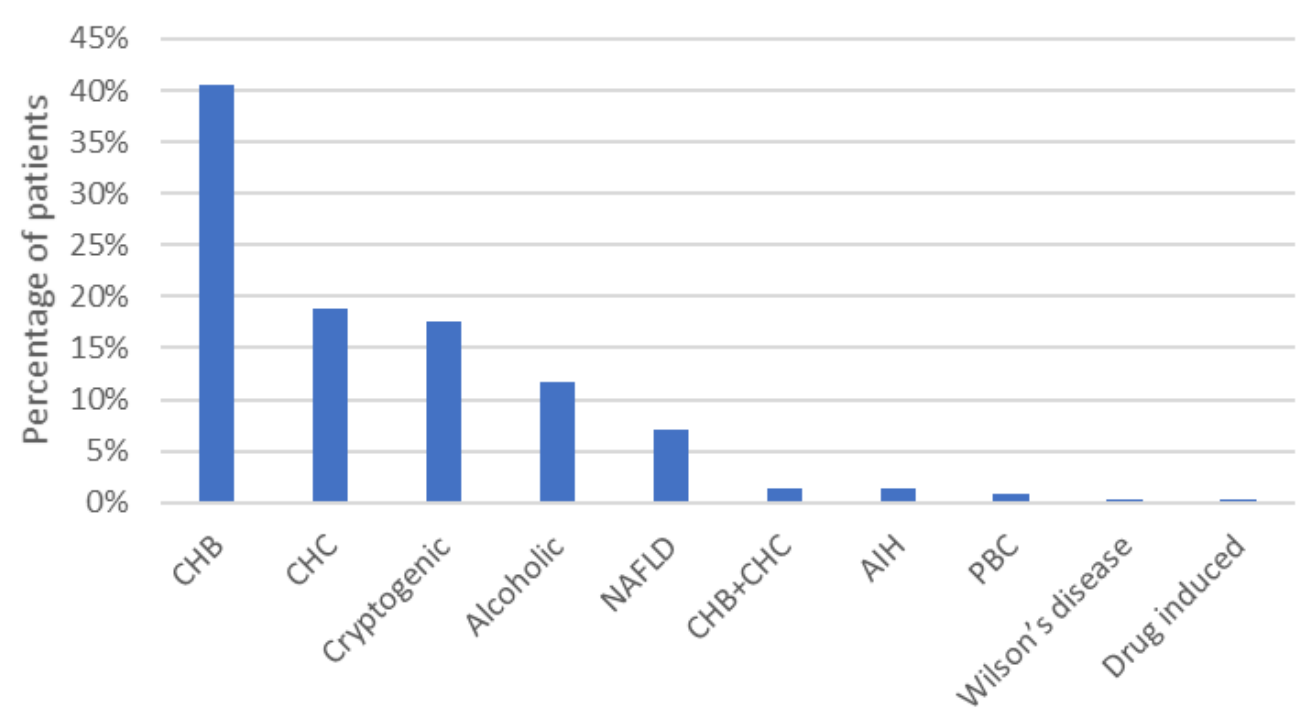

Aetiology of liver cirrhosis

Figure 1 Overall aetiology distribution of liver cirrhosis. $\mathrm{CHB}=$ chronic hepatitis $\mathrm{B}$; $\mathrm{CHC}=$ chronic hepatic $\mathrm{C}$; $\mathrm{NAFLD}=$ non-alcoholic fatty liver disease; $\mathrm{AIH}=$ autoimmune $\mathrm{AIH}=$ autoimmune hepatitis; $\mathrm{PBC}=$ primary biliary cirrhosis

Figure 2 demonstrated variations in terms of causes leading to liver cirrhosis among different age groups. Nonetheless, after performing statistical analysis (one-way ANOVA), no statistical significance $(\mathrm{p}=0.0878)$ was observed.

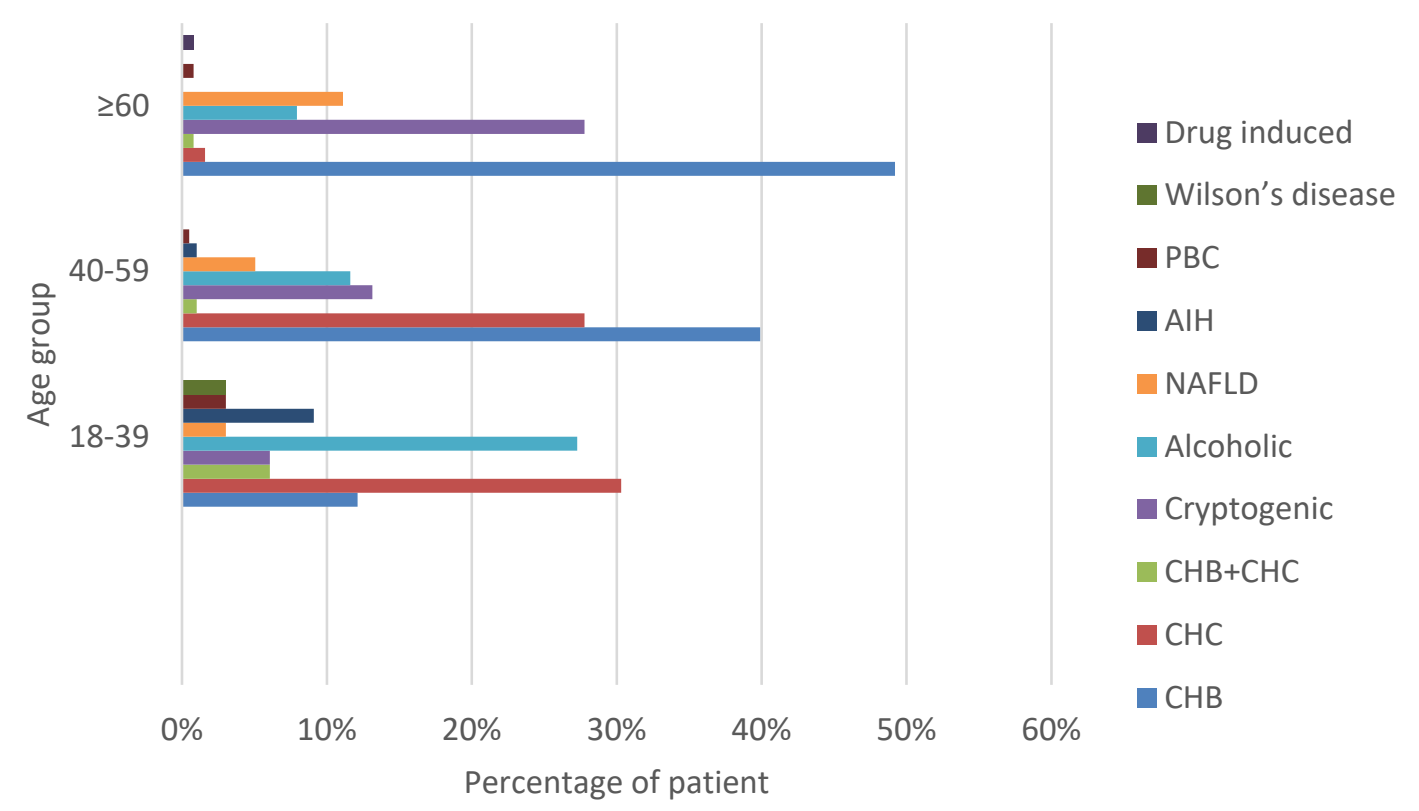

Figure 2 Distribution of aetiology among different age groups. $\mathrm{CHB}=\mathrm{CHB}=$ chronic hepatitis $\mathrm{B}$; $\mathrm{CHC}=$ chronic

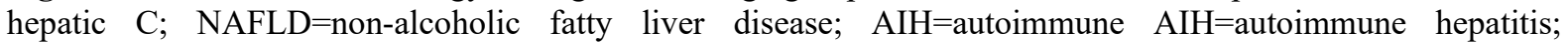
$\mathrm{PBC}=$ primary biliary cirrhosis

Among these 357 patients with liver cirrhosis, $55.7 \%$ of patients were male, with the male to female ratio of $1.26: 1$. The distribution of aetiology of for male and female was illustrated in Fig. 3, and further statistical analysis (paired t test) did not show statistically significant difference 
between these two genders $(\mathrm{p}=0.3598)$. For both genders, CHB (34.1\% in male and $48.7 \%$ in female) was found to be the leading cause to develop liver cirrhosis.

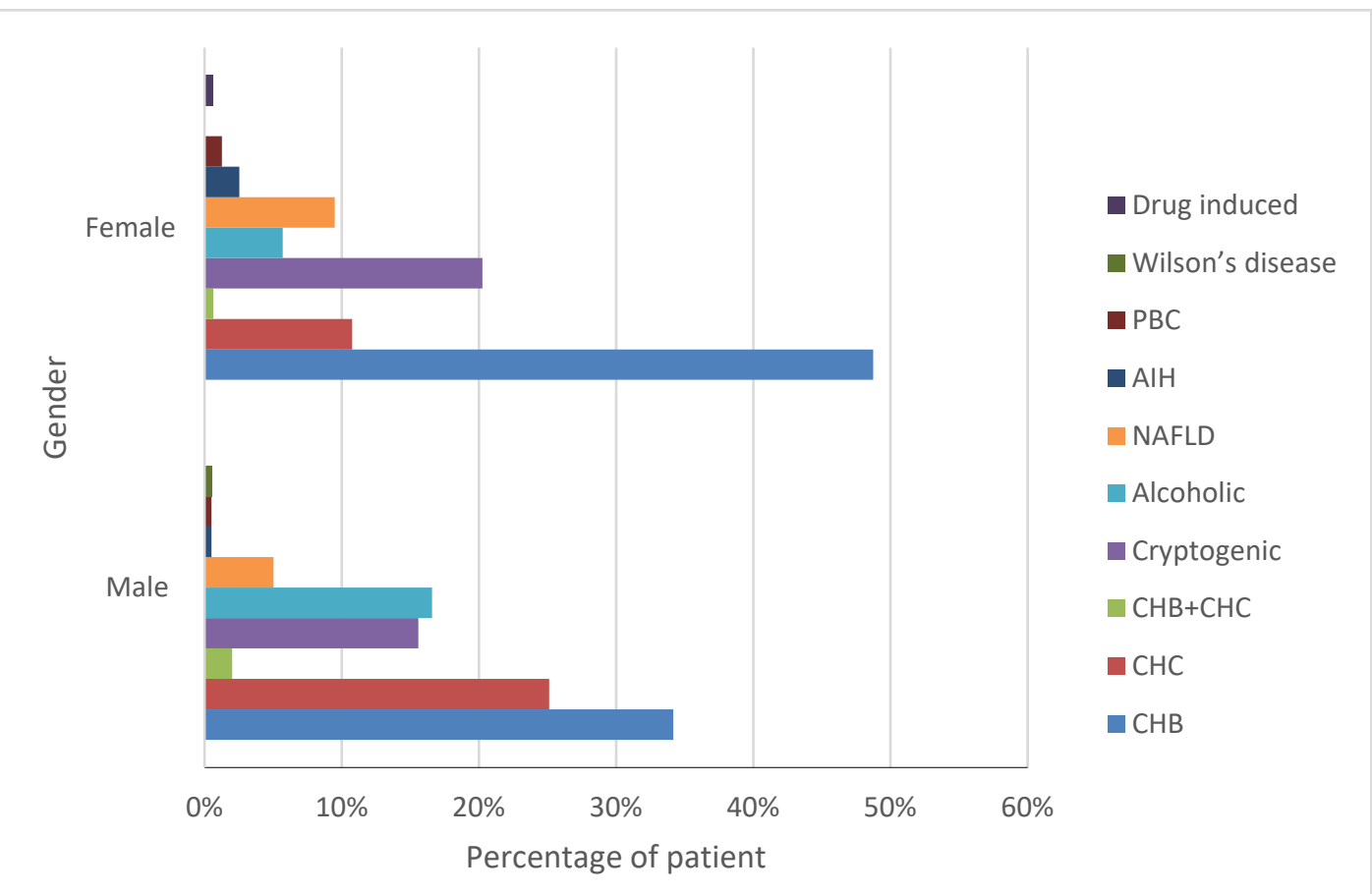

Figure 3 Distribution of aetiology among males and females. $\mathrm{CHB}=\mathrm{CHB}=$ chronic hepatitis $\mathrm{B}$; $\mathrm{CHC}=$ chronic

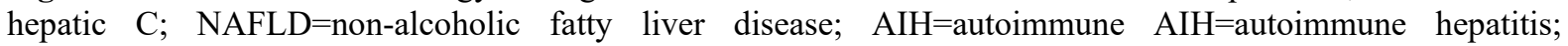
$\mathrm{PBC}=$ primary biliary cirrhosis

The four leading causes of liver cirrhosis namely $\mathrm{CHB}, \mathrm{CHC}$, cryptogenic liver diseases, and alcoholic were analysed on their distribution among the major races in this study. As shown in Fig. 4, CHB was the predominant aetiology among Chinese, contributing to $62.2 \%$. For Malay, CHB was also the most common cause but with lower contribution $(43.8 \%)$ as compared with that of Chinese. Besides, CHC was the second most common cause $(34.9 \%)$ among Malay. On the other hand, alcohol consumption (39.6\%) and cryptogenic liver diseases $(34.0 \%)$ were the major causes among Indian patients. With regard to other races, $\mathrm{CHB}$ was again the major cause (45\%), followed by alcohol consumption (30\%). However, these variations were without statistical significance $(\mathrm{p}=0.4262)$. 
International Journal of Public Health Research Vol 12 No 1 2022, pp (1493-1501)

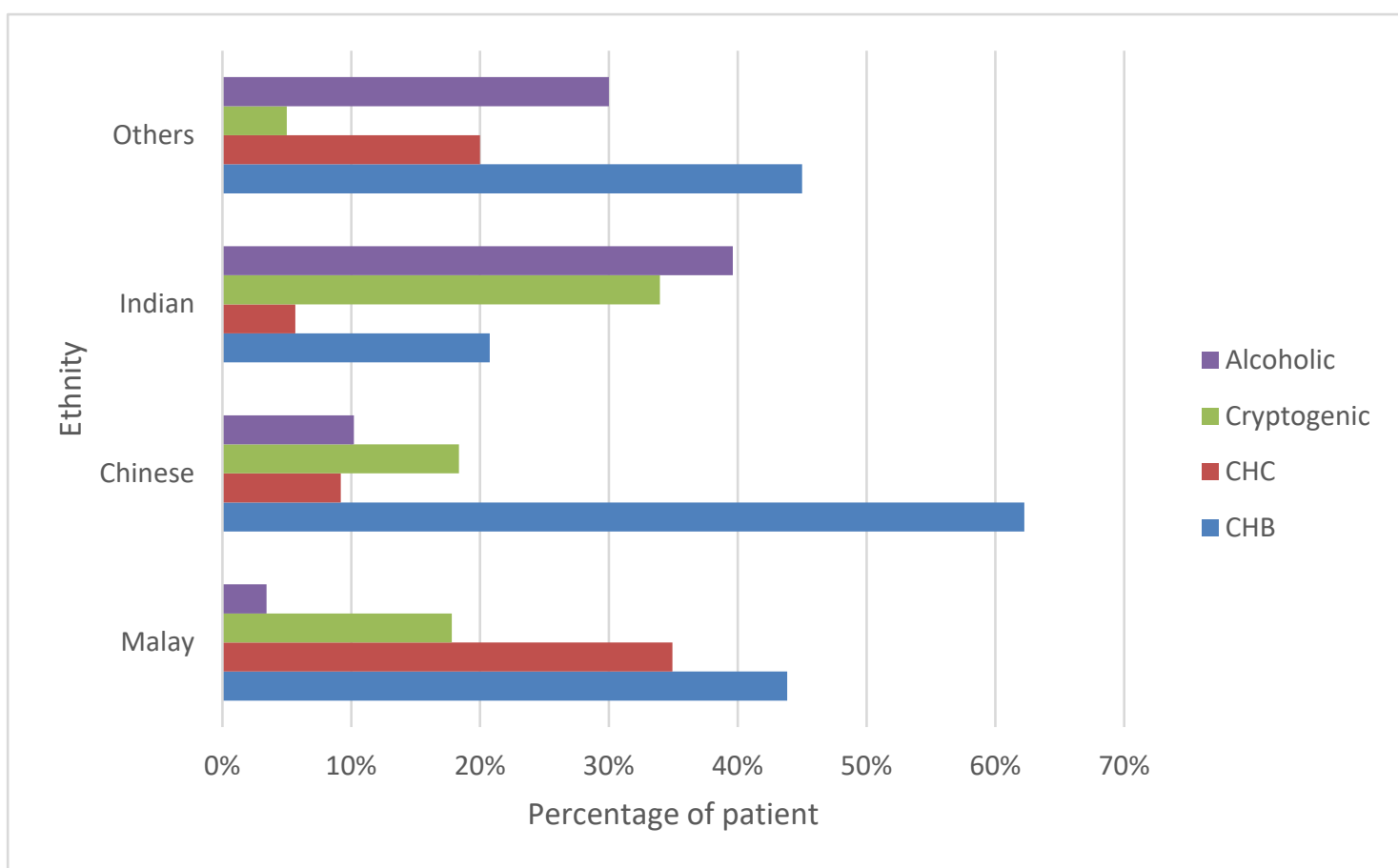

Figure 4 Distribution of aetiology among races. $\mathrm{CHB}=\mathrm{CHB}=$ chronic hepatitis $\mathrm{B}$; $\mathrm{CHC}=$ chronic hepatic $\mathrm{C}$; $\mathrm{NAFLD}=$ non-alcoholic fatty liver disease; $\mathrm{AIH}=$ autoimmune $\mathrm{AIH}=$ autoimmune hepatitis; $\mathrm{PBC}=$ primary biliary cirrhosis

Staging or severity of cirrhosis at the time of diagnosis

$61.9 \%$ of the patients had compensated cirrhosis with Child-Pugh A (least severe). This was followed by $23.8 \%$ with Child-Pugh B (moderate severe), and $14.3 \%$ with Child-Pugh C (most severe).

$80.4 \%(\mathrm{~N}=287)$ of the cirrhotic patients had performed at least one OGDS surveillance, with
$28.6 \%(82 / 287)$ of them had endoscopic evidence of portal hypertension.

About one third (115 out of $357,32.2 \%$ ) of cirrhotic patients had at least one hospitalisation due to complication during this study period (See Fig. 5). Among the complications, ascites was the most common $(47.0 \%)$.

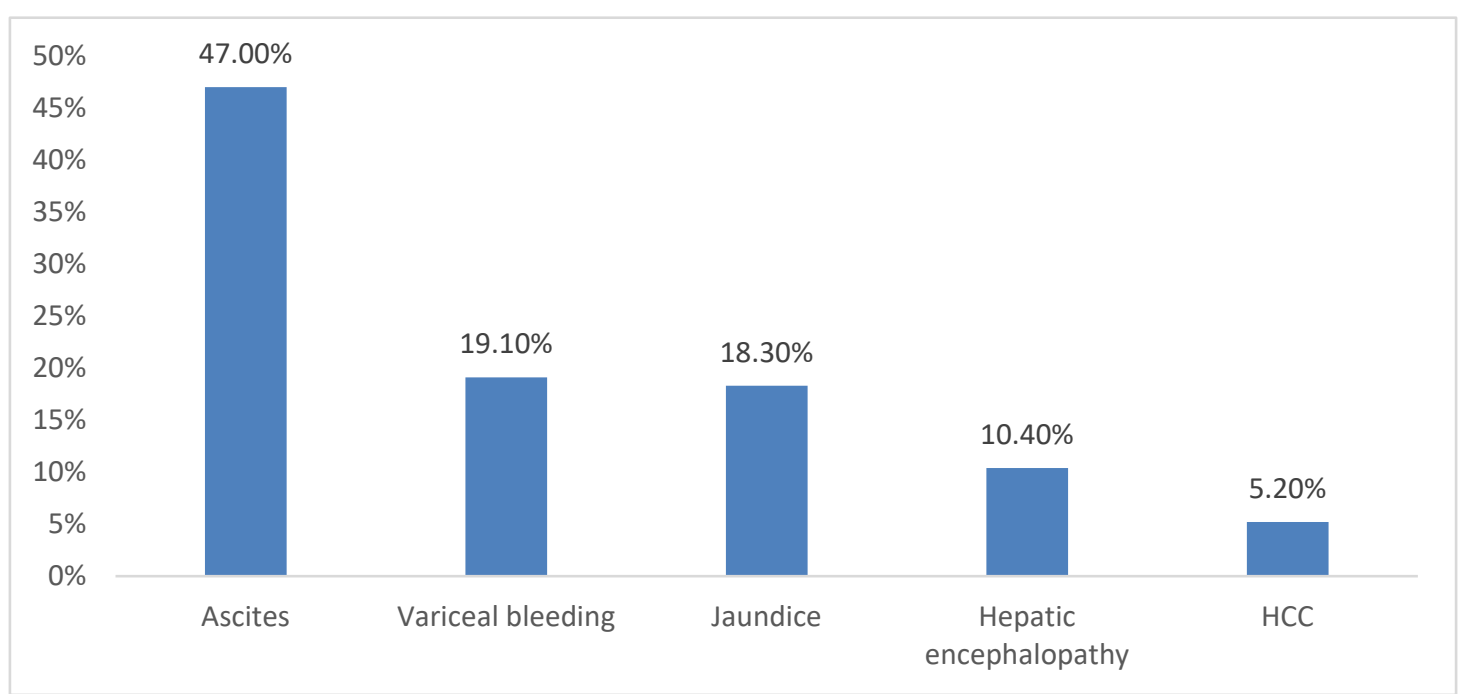

Figure 5 Presenting complications of liver cirrhosis requiring hospitalizations

During the clinic follow up, 41 of these 357 liver cirrhosis patients $(11.5 \%)$ had developed concurrent HCC. The initial causes of liver cirrhosis for these 41 patients were $\mathrm{CHB}, \mathrm{CHC}, \mathrm{CHB}+\mathrm{CHC}$, cryptogenic and alcoholic liver diseases (Table 1). 


\section{Clinical Pattern of Liver Cirrhosis among Malaysians}

Table 1 Incidence of HCC together with the aetiology during the clinic follow up

\begin{tabular}{lr}
\hline \multicolumn{1}{c}{ Aetiology } & $\begin{array}{r}\mathrm{n} \text { of } \mathrm{HCC} / \mathrm{n} \text { of cirrhosis }(\%) \\
(\mathrm{n}=41 / 357,11.5 \%)\end{array}$ \\
\hline $\mathrm{CHB}$ & $23 / 145(15.9 \%)$ \\
$\mathrm{CHC}$ & $4 / 67(6.0 \%)$ \\
$\mathrm{CHB}+\mathrm{CHC}$ & $1 / 5(20 \%)$ \\
Cryptogenic & $8 / 63(12.7 \%)$ \\
Alcoholic & $5 / 42(11.9 \%)$ \\
\hline
\end{tabular}

\section{DISCUSSION}

According to our study findings (Fig. 1), 60.8\% of cirrhotic patients were caused by viral hepatitis, with $\mathrm{CHB}$ as the most common cause of cirrhosis. This was consistent with other Malaysian studies. ${ }^{19,}{ }^{20}$ In 2018, the incidence rate of CHB in Malaysia had increased from 2.26 per 100,000 in 2010 to 14.52 per 100,000 population, while the incidence rate of CHC was 8.65 per $100,000 .{ }^{21}$ Although hepatitis B immunization coverage among the new-borns in Malaysia was reported up to $99.16 \%$ in $2018^{21}$, and some patients with $\mathrm{CHC}$ were able to receive the highly effective antiviral treatment at few Malaysian government hospitals since 2018, we can expect the rising trend of viral hepatitis related chronic liver disease (CLD) in the near future. Adults are more likely to have acute viral hepatitis infection through certain activities, such as tattooing, unprotected sexual activities, and intravenous drug use (IVDU). However, their low Hepatitis B vaccination coverage may continue to increase the incidence rate of CHB. In 2017, $0.3 \%$ of foreign workers in Malaysia were reported to have Hepatitis B infection. ${ }^{22}$ The dramatic increasing population of foreign workers, especially those who are illegal, in this country may carry hepatitis virus, and continue to spread the disease silently. Although access to antiviral treatment is improving, it was estimated that only small proportion of patients with hepatitis $\mathrm{C}$ in Malaysia were treated with antiviral drugs. ${ }^{23}$ Therefore, viral hepatitis will remain to be the major cause of CLD in the near future.

Interestingly, cryptogenic liver disease was the third commonest cause of cirrhosis after CHB, $\mathrm{CHC}$ and alcoholic in this study. Literatures suggested that some cryptogenic liver diseases were believed probably due to NAFLD. We noticed that cryptogenic liver diseases were commoner among females, elders and Indian patients, which was also happened in NAFLD. Cryptogenic liver disease is mainly diagnosed when other aetiologies had been excluded. Despite routine blood tests and ultrasound scan, liver biopsy was not routinely performed in most of our cirrhotic patient's prior the making diagnosis of cryptogenic liver disease. Therefore, this could be one of the limitations of our study.

The current study found that majority of cirrhotic patients were 40-59 years old with the mean age of 54 years (Fig. 2). This corresponded to
Qua et al's study that the mean age of cirrhotic patients in Malaysia was 58.8 years old. ${ }^{19}$ In our study, we observed that the prevalence of $\mathrm{CHB}$ infection among cirrhotic patients increased with age. Few reasons could explain this finding. Firstly, national vaccination programme was only launched in Malaysia starting 1989, hence those who were current above thirty-year-old of age may had never received vaccination before. Therefore, $\mathrm{CHB}$ is expected still to be the leading cause of cirrhosis for next twenty years and there will be a decline in incidence perhaps thirty years from now. Secondly, the increasing rate of $\mathrm{CHB}$ infection among adults suggested the horizontal transmission is commoner during the adulthood. However, the prevalence of $\mathrm{CHC}$ infection was commoner among cirrhotic patients of 18-59 years old, but lower in the age group above 60 years old. This was different with some other countries such as Italy ${ }^{24}$ and Japan ${ }^{25}$, where they observed the lower prevalence of CHC infection among young adults, but increasing prevalence during aging. This suggested that risk of being infection by hepatitis $\mathrm{C}$ virus is the greatest among those of reproductive age in which IVDU was the most common risk factor in Malaysia. ${ }^{26,27}$

Male made up the majority of alcoholic cirrhosis cases $(78.6 \%)$ and $\mathrm{CHC}$ cirrhosis cases $(74.6 \%)$ (Fig. 3). It is evident from this study that more heavy alcohol drinking occurred among males, which was consistent with National Health and Morbidity Survey 2017. Besides, male preponderance among patients with $\mathrm{CHC}$ was likewise reported at Kuala Lumpur ${ }^{28}$ and Kedah. ${ }^{29}$ IVDU was most likely the risk factor for $\mathrm{CHC}$ infection among male patients.

By further studying the epidemiology of liver cirrhosis according to ethnicity (Fig 4), CHB was found to be the predominant aetiology of cirrhosis among Chinese due to their highest prevalence of $\mathrm{CHB} ;{ }^{19} \mathrm{CHC}$ cirrhosis was more common among Malays, ${ }^{22}$ which could be explained by more drug abusers were Malays, and IVDU was reported as the major route of $\mathrm{HCV}$ transmission in Malaysia; ${ }^{26,27}$ whereas alcohol was the main aetiology among Indians, presumably Indians consume alcohol at a larger amount and more frequently. However, it is crucial to rule out NAFLD occurring in those with excessive alcohol consumption. 
$61.9 \%$ of the patients had compensated cirrhosis with Child-Pugh A at the time of diagnosis. About one third of patients had at least one hospitalisation due to decompensation or complication during this study period (Fig. 5). Abdominal distension due to ascites was the commonest complication. This was similarly reported in existing literatures. ${ }^{30,} 31$ However, no documentation regarding the attempt of abdominal paracentesis or prevalence of spontaneous peritonitis (SBP) in our study. Our preliminary data showed that majority of the cirrhotic patients had received at least one OGDS evaluation. However, only $28.6 \%$ of them had endoscopic finding of portal hypertension. This was lower than other literatures that reported gastroesophageal varices were detected in about half of the cirrhotic patients. ${ }^{13}, 14$

Patients with cirrhosis are at significant risk of developing HCC. ${ }^{32}$ Our observations (Table 1) confirmed that cirrhotic patients associated with CHB were at high risk for developing HCC, which was comparable to previous studies. ${ }^{33-35}$ This could be the reflection of existing significant $\mathrm{CHB}$ disease burden itself.

There were several practical limitations to our study. This was the single centre experience, which may not reflect the real situation of nationwide liver disease. The diagnostic criteria were not perfect, in which patients with more than one overlapping aetiology were categorized based on the predominant aetiology. Besides, histological assessment should be made compulsory in all the cirrhotic patients during making diagnosis of cryptogenic liver cirrhosis or NAFLD. Adherence to $\mathrm{HCC}$ surveillance should be further evaluated in the future study.

\section{CONCLUSION}

We showed that $\mathrm{CHB}$ remains the most common etiologic factor among the cirrhotic patients attending a tertiary hospital in Selangor, Malaysia. Current study shared a useful sketch of the aetiologies, and clinical patterns of CLD in Malaysia. Compulsory vaccination among infants and improving Hepatitis B vaccination coverage in high-risk population groups include $\mathrm{HCWs}$, contacts of HBsAg-positive persons, and foreign workers should be prioritized. Larger cohort studies on the aetiology of cirrhosis from other states in Malaysia are required to improve the understanding of liver cirrhosis aetiology in this region.

\section{ACKNOWLEDGEMENT}

The authors acknowledge support from the Ethics Committee for the approval of ethics and Ministry of Health Malaysia as well as Medical Department of Serdang Hospital for the approval of conducting this study.

\section{CONFLICT OF INTEREST}

There is no conflict of interests regarding the publication of this article.

\section{REFERENCES}

1. Benvegnu L, Gios M, Boccato S, Alberti A. Natural history of compensated viral cirrhosis: a prospective study on the incidence and hierarchy of major complications. Gut. 2004;53: 744-9.

2. Setiawan VW, Stram DO, Porcel J, Lu SC, Le Marchand L, Noureddin M. Prevalence of chronic liver disease and cirrhosis by underlying cause in understudied ethnic groups: The multiethnic cohort. Hepatology. 2016;64(6): 1969-77.

3. Younossi ZM, Stepanova M, Afendy M, Fang Y, Younossi Y, Mir H, et al. Changes in the prevalence of the most common causes of chronic liver diseases in the United States from 1988 to 2008. Clin Gastroenterol Hepatol. 2011;9: 524-530; quiz e560.

4. Wree A, Broderick L, Canbay A, Hoffman HM, Feldstein AE. From NAFLD to NASH to cirrhosis-new insights into disease mechanisms. Nature Reviews Gastroenterology \& Hepatology. 2013;10(11): 627-36

5. Fung KT, Lai CL, Yuen MF. Etiologies of chronic liver diseases in Hong Kong. European Journal of Gastroenterology \& Hepatology. 2007;19(8): 659-64.

6. Park JW. Hepatocellular carcinoma in Korea: introduction and overview. Korean J Gastroenterol. 2005;45(4): 217-26.

7. Yeole BB. Trends in cancer incidence in esophagus, stomach, colon, rectum and liver in males in India. Asian Pac J Cancer Prev. 2008;9(1): 97-100.

8. Rezaei N, Asadi-Lari M, Sheidaei A, Khademi S, Gohari K, Delavari F. Liver cirrhosis mortality at national and provincial levels in Iran between 1990 and 2015: A meta regression analysis. PLoS One. 2019:15;14(1): e0198449.

9. Fernandes ML, Chan YH, Lim SG. Trends in the incidence of hepatocellular carcinoma in Singapore 1968-2002. Hepatology. 2007;46(4 Suppl 1):418A.

10. Yuen MF, Hou JL, Anuchit C, on behalf of the Asia Pacific Working Party on Prevention of Hepatocellular Carcinoma. Hepatocellular carcinoma in the Asia pacific region. Journal of Gastroenterology and Hepatology. 2010;25: 346-53.

11. Wong SW, Ting YW, Chan WK. Epidemiology of Non-Alcoholic Fatty Liver Disease-Related Hepatocellular Carcinoma and Its Implications. JGH Open. 2018;2(5): 235-241. 
12. Tapper EB, Halbert B, Mellinger J. Rates of and reasons for hospital readmissions in patients with cirrhosis: a multistate population-based cohort study. Clin Gastroenterol

Hepato. 2016;14 ([e2]):1181-8.

13. Smith JL, Graham DY. Variceal haemorrhage: a critical evaluation of survival analysis. Gastroenterology. 1982;82(5Pt 1):968.

14. Garcia-Tsao G, Sanyal AJ, Grace ND, Carey W. Prevention and management of gastroesophageal varices and variceal haemorrhage in cirrhosis. Practice Guidelines Committee of the American Association for the Study of Liver Diseases, Practice Parameters Committee of the American College of Gastroenterology. Hepatology. 2007; 46(3):922.

15. Collier J, Sherman M. Screening for hepatocellular carcinoma. Hepatology. 1998;27(1):273-8.

16. Globocan 2020. [Cited 2021 September 1]. Available from: https://gco.iarc.fr/.

17. Kato Y, Nakata K, Omagari K, Furukawa R, Kusumoto Y, Mori I, et al. Risk of hepatocellular carcinoma in patients with cirrhosis in Japan. Analysis of infectious hepatitis viruses. Cancer. 1994;74: 2234-8

18. Chen CF, Lee WC, Yang HI, Chang $\mathrm{HC}$, Jen CL, Iloeje UH, et al. Changes in serum levels of HBV DNA and alanine aminotransferase determine risk for hepatocellular carcinoma. Gastroenterology. 2011;141:

1240-8.

19. Qua CS, Goh KL. Liver cirrhosis in Malaysia: peculiar epidemiology in a multiracial Asian country. Journal of Gastroenterology and Hepatology. 2011;26(8),1333-7.

20. Kudva MV, Zawawi MM. Chronic liver disease in Kuala Lumpur, Malaysia: a clinical study. Singapore Med J. 1990;31(4): 368-73.

21. Health Facts 2019, Ministry of Health Malaysia. [Cited 2020 April 15]. Available from:

http://www.moh.gov.my/moh/resources/P enerbitan/Penerbitan\%20Utama/HEALTH \%20FACTS/Health\%20Facts\%202019_B ooklet.pdf.

22. Ministry of Health Malaysia. National Strategic Plan for Hepatitis B and C Malaysia 2019-2023. [Cited 15 April 2020]. Available from: http:/www.moh.gov.my/moh/resources/P enerbitan/Pelan\%20Strategik\%20/NSP_H ep_BC_2019_2023.pdf.
23. Hepatitis C Virus Diagnostics Advocacy Workshop Summary Report. 1-3 March 2019.

24. Guadagnino V, Stroffolini T, Rapicetta M, et al. Prevalence, risk factors, and genotype distribution of hepatitis $\mathrm{C}$ virus infection in the general population: $\mathrm{a}$ community-based survey in southern Italy. Hepatology. 1997;26,1006-1011.

25. Okayama A, Stuver SO, Tabor E, et al. Incident hepatitis $C$ virus infection in a community-based population in Japan, $\mathrm{J}$ Viral Hepat. 2002;9: 43-51.

26. Mohamed N, Rashid ZZ, Wong KK, Abdullah SA, Rahman MM. Hepatitis C genotype and associated risks factors of patients at University Kebangsaan Malaysia Medical Centre. Pakistan J Med Sci. 2013; 29:1-5.

27. Ho SH, Ng KP, Kaur H, Goh KL. Genotype 3 is the predominant hepatitis $\mathrm{C}$ genotype in a multi-ethnic Asian population in Malaysia. Hepatobiliary Pancreat Dis Int. 2015; 14:281-6.

28. Suresh RL, Kananathan R, Merican I. Chronic hepatitis C--a study of 105 cases between 1990-2000. Med J Malaysia. 2001;56: 243-7.

29. Tan WL, Goh YH, Muhammad RAH. Demographic characteristics and intravenous drug use among hepatitis C patients in the Kota Setar district, Kedah, Malaysia. Epidemiol Health. 2015;37: e2015032.

30. Turnes J, Garcia-Pagan JC, Abraldes JG, et al. Pharmacological reduction of portal pressure and long-term risk of first variceal bleeding in patients with cirrhosis. Am J Gastroenterol. 2006;101(3): 506-12.

31. Bell H, Jahnsen J, Kittang E, et al. Longterm prognosis of patients with alcoholic liver cirrhosis: A 15-year follow-up study of 100 Norwegian patients admitted to one unit. Scand J Gastroenterol. 2004;39(9): 858-63.

32. Colombo M, de Franchis R, Del Ninno E, Sangiovanni A, De Fazio C, Tommasini M, et al. Hepatocellular carcinoma in Italian patients with cirrhosis. N Engl J Med. 1991;325: 675-80.

33. Goh KL, Razlan H, Hartono JL, Qua CS, Yoong BK, Koh PS, Abdullah BJ. Liver cancer in Malaysia: epidemiology and clinical presentation in a multiracial Asian population. J Dig Dis. 2015;16(3):152-8.

34. Raihan R, Azzeri A, H Shabaruddin F, Mohamed R. Hepatocellular Carcinoma in Malaysia and Its Changing Trend. Euroasian J Hepatogastroenterol. 2018;8(1): 54-6. 
International Journal of Public Health Research Vol 12 No 1 2022, pp (1493-1501)

35. Norsa'adah B, Nurhazalini-Zayani CG.

Epidemiology and survival of hepatocellular carcinoma in north-east Peninsular Malaysia. Asian Pac J Cancer Prev. 2013; 14(11): 6955-9. 